\title{
The development of national injury prevention policy in the Australian health sector: and the unmet challenges of participation and implementation
} Rebecca Mitchell*1 and Rod McClure ${ }^{2}$

\author{
Address: ${ }^{1}$ NSW Injury Risk Management Research Centre, University of New South Wales, Sydney, Australia and ${ }^{2}$ School of Medicine, Griffith \\ University, Queensland, Australia \\ Email: Rebecca Mitchell* - r.mitchell@unsw.edu.au; Rod McClure - r.mcclure@griffith.edu.au \\ * Corresponding author
}

Published: 23 October 2006

Australia and New Zealand Health Policy 2006, 3:II doi:I0.1 I86/I743-8462-3-II
Received: 06 March 2006

Accepted: 23 October 2006

This article is available from: http://www.anzhealthpolicy.com/content/3/I/I I

(C) 2006 Mitchell and McClure; licensee BioMed Central Ltd.

This is an Open Access article distributed under the terms of the Creative Commons Attribution License (http://creativecommons.org/licenses/by/2.0), which permits unrestricted use, distribution, and reproduction in any medium, provided the original work is properly cited.

\begin{abstract}
For the last 20 years injury prevention policy in Australia has been hampered by poor consultation practices, limited stakeholder involvement, inadequate allocation of resources, poor implementation, and an absence of performance measures. This paper describes the development of injury prevention policy in Australia from its beginnings in 1981 to the current day and considers what measures should be undertaken to create an effective platform for the reduction of the burden of injury in Australia.

The National Injury Prevention and Safety Promotion Plan 2004-2014, released in 2005, needs to be supported by a whole of government commitment to the reduction of injury. The Council of Australian Governments would be an ideal forum to monitor progress, supported by a crossgovernment Ministerial Council.
\end{abstract}

\section{Background}

Approximately 7,800 Australians die each year from injury [1]. Evidence suggests that there are $\$ 1.3$ trillion of potential health gains to be made from reducing injuries alone [2]. Reducing injuries in Australia by just under onethird would equal savings of over $\$ 370$ billion which is greater than Australia's total net foreign debt [2].

In July 2005, the Australian Health Ministers approved release of the National Injury Prevention and Safety Promotion Plan 2004-2014. The policy is the culmination of activity within the Australian health sector that spans two decades. In this paper, we describe the critical features of the period of national injury prevention policy development since the Better Health Commission report of 1986, and argue that low levels of community participation and inadequate government commitment to implementation has compromised the effectiveness of this policy. We conclude that unless there is a genuine cross sectoral involvement in an adequately resourced whole of government commitment to implementing the National Injury Prevention and Safety Promotion Plan 2004-2014 then this healthbased national injury prevention policy will have no impact on the population level indicators of injury in Australia.

The history of national injury prevention policy development within the health sector in Australia

The development of national injury prevention policy in Australia (Table 1) began in 1981 when the World Health Organization (WHO) published the Global Strategy for 
Health for All by the Year 2000 [3]. In response to this call for all WHO Member States to develop national policies, strategies and action plans to improve health and to monitor the effectiveness of their progress against specified actions, the then Federal Minister for Health, Dr Neal Blewett, created the Better Health Commission in 1985 [4]. The Commission was asked to report on the current health status of the Australian population and to focus on the development of health-related policy relating to the prevention of disease and injury $[5,6]$.

In 1986, the Better Health Commission published Looking Forward to Better Health in three volumes $[5,7,8]$. Among the Commission's recommendations were that major prevention activities should concentrate on the three areas of cardiovascular disease, nutrition, and injury. Following the release of the Better Health Commission report, the Australian Health Ministers Advisory Council (AHMAC) established the Health Target and Implementation Committee (HTIC) in 1987 to provide advice regarding how the recommendations from the Better Health Commission report could be implemented [9]. In 1988, the HTIC published Health for All Australians [10] which outlined goals and targets in three main areas: (1) population groups; (2) major causes of illness and death (including injury); and (3) risk factors. The report also included five priority health areas for preventive action of which injury was one. The National Better Health Program (NBHP) was established in 1988 to oversee the implementation of the strategies outlined in the HTIC report.

Four years after its creation, a review of the NBHP was conducted and found that while progress had been made in some areas, there were limitations of the approach to the goals and targets suggested in the Health for all Australians report $[6,11]$. The review identified that the goals and targets listed in the report had not been widely adopted. It highlighted the strong need for the health system to be fully engaged in both the identification and monitoring of any health targets, in the development of accountability measures, and in the development of strategies for addressing both the social and environmental determinants of health $[4,12,13]$. As an added stimulus for the development of a consistent national approach to health goals and targets, in 1992 the Medicare Agreements Act required the Commonwealth and the State and Territory Governments to have developed national health goals and targets by 30 June 1994 [14].

Goals and targets for Australia's Health in the year 2000 and beyond was commissioned by the Federal Government from academics in the Department of Public Health at the University of Sydney and it was published in 1993 [13]. This report revised the goals and targets of Health for all Australians into four principal areas: (1) mortality, morbidity and quality of life; (2) healthy lifestyles and risk fac-

Table I: Development of injury prevention policy in Australia by the health sector

\begin{tabular}{|c|c|}
\hline Year & Initiative \\
\hline 1981 & Global Strategy for Health for All by the Year 2000 published by World Health Organization. \\
\hline 1985 & Better Health Commission established to respond to WHO initiative. \\
\hline 1986 & Looking Forward to Better Health published by the Better Health Commission. \\
\hline 1987 & Health Targets and Implementation (Health for All) Committee established. \\
\hline 1988 & Health for all Australians. Report of the Health Targets and Implementation (Health for All) Committee to Australian Health Ministers published. \\
\hline 1988 & Establishment of the National Better Health Program. \\
\hline 1991 & Review of the National Better Health Program. \\
\hline 1992 & $\begin{array}{l}\text { Medicare Agreements Act } 1992 \text { requires Commonwealth and State and Territory Governments to have developed national health goals } \\
\text { and targets by } 30 \text { June } 1994 .\end{array}$ \\
\hline 1993 & Goals and Targets for Australia's Health in the Year 2000 and Beyond published. \\
\hline 1993 & National Health Summit held. \\
\hline 1994 & Better Health Outcomes for Australia published and Better Health Outcomes Overseeing Committee established. \\
\hline 1996 & National Health Priority Area initiative established. \\
\hline 1996 & National Public Health Partnership Group formed. \\
\hline 1997 & National Injury Prevention Advisory Council established. \\
\hline 1997 & National Health Priority Area: Injury Prevention and Control report published. \\
\hline 1999 & $\begin{array}{l}\text { Directions in Injury Prevention. Report I: Research Needs and Directions in Injury Prevention. Report 2: Injury Prevention Interventions Good Buys for } \\
\text { the Next Decade published. }\end{array}$ \\
\hline 2000 & Strategic Injury Prevention Partnership established as a subcommittee of NPHPG. \\
\hline 2001 & National Injury Prevention Plan Priorities for 200I-2003 and National Injury Prevention Plan Priorities for 200 I-2003 Implementation Plan published. \\
\hline 2004 & Evaluation of the National Injury Prevention Plan Priorities for 200 I-2003. \\
\hline 2005 & National Injury Prevention and Safety Promotion Plan 2004-20/4 endorsed. \\
\hline 2005 & National Aboriginal and Torres Strait Islander Safety Promotion Plan 2004-20I4 endorsed. \\
\hline 2005 & National Falls Prevention for Older People Plan: 2004 onwards endorsed. \\
\hline
\end{tabular}


tors; (3) health literacy and life skills; and (4) healthy environments.

Goals and targets for Australia's Health in the year 2000 and beyond adopted a more social view of health than previous health-related goal and target setting reports. It contained over 100 goals and 600 specific targets, 76 targets related to injury prevention, including transport-related injuries, suicide, interpersonal violence, injuries in a residential setting, and product- and sport-related injuries. Targets for safe behaviours, such as wearing helmets while bicycling and mouthguard wearing during contact sports, were also set $[6,13]$. Reviewing the report at a National Health Summit in April 1993, the Australian Health Ministers agreed that the goals and targets outlined in the report should be included within a broader framework of national health policy $[4,11,12]$. Subsequently, a joint working group of AHMAC and the National Health and Medical Research Council (NHMRC) was established to identify some initial national health focus areas for action. The working group identified four priority health areas: (1) cardiovascular disease; (2) cancer; (3) injury; and (4) mental health, and implementation groups were established for these areas.

In 1994, the Better Health Outcomes for Australians report was published which brought together the work of the four implementation groups[14]. This report provided a number of goals, strategies, and indicators for these four priority health areas, of which 22 goals and 29 targets related directly to injury prevention, in the areas of transport-related injuries, work-related injury, falls in older persons and in young children, product- and sport-related injury, interpersonal violence, poisoning, burns and scalds, and drowning. This report also included two goals related to post injury management. Following the release of the report, the AHMAC established the Better Health Outcomes Overseeing Committee (BHOOC) $[4,11]$. One year later, the BHOOC reviewed the national health goals and targets process and identified a number of issues. It appeared that the complexity of the goals and targets were a problem, the number of indicators were too large (over 140 indicators across four health areas), and no national reporting requirements existed [4]. Following this review, the National Health Priority Area (NHPA) initiative was established by the Australian Health Ministers in July 1996 [4].

In 1996, AHMAC agreed that a report should be prepared on each of the four health priority areas every two years to provide an overview of the burden and the key issues relating to each area [15]. The AHMAC also agreed that diabetes should be added to the health priority areas, making a total of five priority areas and that a National Public Health Partnership Group (NPHPG) should be formed in an attempt to develop a national coordinated approach to public health. In 1997, the first report on Injury Prevention and Control was published as part of the series on national health priority areas [15]. In the same year, the National Injury Prevention Advisory Council (NIPAC) was established to provide independent advice to the then Commonwealth Department of Health and Aged Care (DHAC) and to Health Ministers on appropriate strategies to reduce the incidence and severity of injury in Australia. Members of NIPAC included representatives from DHAC, the state and territory health departments, injury prevention researchers, and practitioners.

In 1999, NIPAC and the DHAC produced two reports describing proposed directions in injury prevention, including research needs and effective interventions for injury prevention $[16,17]$. These reports provided an overview of injury in Australia, described known effective injury prevention measures, and outlined opportunities for investment in injury prevention strategies that were likely to be the most cost-effective. During this period, NIPAC developed the first National Injury Prevention Plan, which contained four priority areas for injury prevention: (1) falls in older people; (2) falls in children aged 14 years or less; (3) drowning and near-drowning; and (4) poisoning in children aged four years or less.

The national plan and its accompanying implementation plan were not published until $2001[18,19]$ following the demise of the NIPAC and the formation of the Strategic Injury Prevention Partnership (SIPP) in August 2000. SIPP was developed as a subcommittee of the NPHPG, and consisted of representatives of DHAC, State and Territory Health Departments, the Australian Institute of Health and Welfare, the Consumer Safety Unit of the Australian Treasury Department, and the Australian Injury Prevention Network.

In 1999, a review of the NHPA initiative found wide support for the continuation of the initiative and a number of recommendations were made, including the need to give greater emphasis to the identification and promotion of evidence-based prevention strategies, and the need for the provision of timely and appropriate indicators to monitor performance and implementation of NHPA strategies [4]. Following this review, asthma, in August 1999 and arthritis and musculoskeletal conditions in July 2002 became the sixth and seventh national health priority areas, respectively [4]. In 2004, a review of the first national injury prevention plan was released. Although the terms of reference of this review were limited, the finding of the review concluded that the plan was created following ineffective consultation, was confined only to the areas of injury prevention over which the health sector had influ- 
ence, did not fully engage injury prevention stakeholders, lacked resources for implementation, appropriate performance measures to gauge progress were absent, and thus the plan was unlikely to have any significant effect on rates of injury-related morbidity and mortality in Australia [20].

In 2005, SIPP submitted a ten year National Plan for Injury Prevention and Safety Promotion to the Australian health ministers. The National Injury Prevention and Safety Promotion Plan 2004-2014 [21] was largely based on both the New Zealand and Canadian Injury Prevention Strategies and identifies two main goals - achieving a positive safety culture and creating safe environments, ten underlying principles, eight priority areas and 71 priority activities, rather than setting specific targets. It represents a return to a population-based focus and includes as its priorities: children, youth and young adults, adults, older people, rural and remote populations, and Aboriginal and Torres Strait Islander peoples. One risk factor, alcohol, is identified as a priority area, along with the core feature of the establishment and maintenance of a national strategic framework for the prevention of injuries. The plan was endorsed by the Health Ministers and SIPP was immediately dissolved.

\section{The Future of the National Injury Prevention and Safety Promotion Plan 2004-20I4}

While not limited to government activity, the term policy tends to be defined as 'government action'[22] and more specifically, 'an action which employs governmental authority to commit resources in support of preferred values' [23]. Although committees have been formed, policy documents written and reviews undertaken, as demonstrated in the above section, both the 'action' and 'commit resources' components of the definition have largely been absent from the 20 year history of injury prevention policy in Australia.

While injuries are treated within the health system, the risk factors for injury (eg. environmental, social or objectspecific) and the creation of legislation and standards that aim to prevent injuries largely lie outside the jurisdiction of the health sector. For instance, in Australia many policy and legislative factors can affect drowning incidence rates and these are beyond the control of any one government or non-government agency. For example, in NSW, the NSW Swimming Pool Act 1992 and its associated Regulation 1998 are enforced by the NSW Department of Local Government; safe boating is regulated by NSW Maritime and the NSW Water Police; the promotion of water and surf safety is conducted by the NSW Department of Sport and Recreation, Surf Life Saving, Royal Life Saving, Austswim, and the Australian and Professional Ocean Lifeguards Association (APOLA); rural water safety and dam safety is promoted by Farmsafe NSW and WorkCover NSW; and medical retrieval and hospital care is provide by the NSW Ambulance Service, the Royal Flying Doctor Service of Australia, and the NSW Department of Health. If all of these agencies in only one state represent different facets of only one injury area, how then should injury prevention efforts be structured at a national level for the best and most cost effective results?

A 'whole of government' approach to the prevention of injuries is needed. Government agencies (and non-government agencies) must work collaboratively if the burden of injuries is to be significantly reduced [24]. A whole of government approach would ultimately reduce duplication, focus resources, promote the best use of skills and expertise, and encouraged sustainability of effort through the strengthening of cross-government networks and partnerships. However, the adoption of a whole of government approach to injury prevention would have implications for the design of government processes, as it would likely involve the integration of planning across government for injury prevention programs, the development of intergovernmental partnership agreements between agencies, the creation of a format for pooled resourcing for injury prevention efforts, the enhancement of injury surveillance practices, and the development of structured key cross-government performance indicators.

With the launch of the National Injury Prevention and Safety Promotion Plan 2004-2014[21] it is now of vital importance that this policy be progressed to include a whole of government commitment to establishing within each agency the process of cross-government collaboration needed to implement the plan.

In New Zealand, the implementation plan for the New Zealand Injury Prevention Strategy is the responsibility of the New Zealand Cabinet who report to the New Zealand Parliament [25]. In Australia, an implementation plan for the National Injury Prevention and Safety Promotion Plan [21] has not even been developed.

Ownership, commitment and national coordination of sustained injury prevention efforts needs to be at the highest level and it is recommended that the Council of Australian Governments (COAG) would be an ideal forum to monitor and discuss cross-government actions in the implementation of injury prevention policy. The COAG has previously discussed some aspects of injury prevention policy, including issues surrounding gun control, domestic violence, child protection, and marine safety[26]. It is recommended that the governance of the implementation of the National Injury Prevention and Safety Promotion Plan 2004-2014 [21] be placed with COAG. The formation of a cross-government Ministerial 
Council could assist in providing advise to COAG on injury prevention priority areas, best use of resources for cost-effective results and integration of planning of prevention activities. Supporting documentation on the incidence of injury in Australia, the development of performance measures and injury indicators could come from enhanced resourcing of already existing bodies, such as the National Injury Surveillance Unit.

Without the allocation of sufficient resources, and the development of an appropriate national governance and performance management structure as described above, the National Injury Prevention and Safety Promotion Plan 2004-2014 [21] is unlikely to meet its goals. Through the engagement of all sectors of government in a cross-government Ministerial Council and steerage by the peak intergovernmental forum, COAG, the impetus for national coordination of injury prevention efforts is strengthened and the commitment of all sectors of government to the reduction of injury is emphasised.

Ultimately, the measure of effectiveness of any national public health policy is a decrease in the population burden and associated costs of the relevant health condition. The dramatic decline in transport-related injuries since 1986 (18.0 per 100,000 population in 1986 to 7.9 per 100,000 population in 2004 [27]) demonstrates the scope for prevention in the injury field. This decline can be directly attributed to the National Road Safety Strategy, improvements in trauma management, and consequent substantial commitments at state and territory government levels by the departments of roads, transport and police. If the National Injury Prevention and Safety Promotion Plan 2004-2014 [21] is to lead to a decrease in the incidence of injury then similar effort needs to be mounted for non-transport related injury.

\section{Conclusion}

Injuries are preventable. Yet, after two decades of national policy development, injuries remain the leading cause of death for Australians under the age of 44 [1]. The National Injury Prevention and Safety Promotion Plan 2004-2014 [21] has recently been endorsed by the Australian Health Ministers to guide a coordinated national response to the problem of injury. A concerted effort must now be made by the signatories to this national document to honour their commitment, as prescribed in the plan, to reducing the injury-related harm that is currently having a serious public health impact on individuals, the community, and the Australian economy.

\section{Declaration of competing interests}

All information on which this article is based is in the public domain. It should be noted however that $\mathrm{R}$
McClure was co-chair of SIPP from 2002 to 2005 and R Mitchell was a member of SIPP during 2004.

The authors declare that they have no competing interests.

\section{Authors' contributions}

RM prepared the first draft of the manuscript. RMc contributed to the development of ideas expressed in the manuscipt and assisted in preparing the final version. Both authors read and approved the final manuscipt.

\section{Acknowledgements}

The authors would like to thank Michele Foster for insightful comments on an early draft of the manuscript.

R Mitchell is supported by a PhD scholarship from Injury Prevention and Control Australia, based at the NSW Injury Risk Management Research Centre.

\section{References}

I. Kreisfeld R, Newson R, Harrison J: Injury Deaths, Australia 2002. In Injury Research and Statistics Series Number 23 Volume INJCAT 65. Adelaide, AlHW; 2004.

2. Access Economics: Exceptional Returns: the Value of Investing in Health R\&D in Australia. Canberra, Australian Society for Medical Research; 2003.

3. World Health Organization: Global Strategy for Health for All by the Year 2000. Geneva, World Health Organization; 198I.

4. National Health Priority Advisory Council: History of the National Health Priority Area Initiative.

5. Better Health Commission: Looking Forward to Better Health: Volume I. Final Report. Canberra, Australian Government Publishing Service; 1986.

6. Wise M, Nutbeam D: National health goals and targets - an historical perspective. Health Promotion Journal of Australia 1994, 4(3):9-13.

7. Better Health Commission: Looking Forward to Better Health: Volume 2. The taskforces and working groups: reports to the Better Health Commission. Canberra, Australian Government Publishing Service; 1986.

8. Better Health Commission: Looking Forward to Better Health: Volume 3. The workshops and consultations: reports to the Better Health Commission. Canberra , Australian Government Publishing Service; 1986.

9. Van Der Weyden M: The burden of disease and injury in Australia: time for action. Medical Journal of Australia 1999, 171:58I-582.

10. Health Targets and Implementation Committee: Health for All Australians. Canberra, Australian Government Publishing Service; 1988.

II. Better Health Outcomes Newsletter: National Health Priority Areas. .

12. Pickering S, Bennett J, Ashpole K: National health goals and targets - the Commonwealth Government's approach to achieving better health outcomes for all Australians. Health Promotion Journal of Australia 1994, 4(3):5-8.

13. Nutbeam D, Wise M, Bauman A, Harris E, Leeder S: Goals and targets for Australia's Health in the Year 2000 and Beyond. Canberra , Commonwealth Department of Health, Housing and Community Services; 1993.

14. Commonwealth Department of Human Services and Health: Better health outcomes for Australians : national goals, targets and strategies for better health outcomes into the next century - Canberra, Commonwealth Department of Human Services and Health,; 1994.

15. Commonwealth Department of Health and Family Services: National Health Priority Areas Report: Injury Prevention and Control. Canberra, Australian Institute of Health and Welfare; 1997. 
16. National Injury Prevention Advisory Council: Directions in Injury Prevention. Report I: Research Needs. Canberra, National Injury Prevention Advisory Council; 1999.

17. National Injury Prevention Advisory Council: Directions in Injury Prevention. Report 2: Injury Prevention Interventions Good Buys for the Next Decade. Canberra, National Injury Prevention Advisory Council; 1999.

18. Commonwealth Department of Health and Aged Care: National Injury Prevention Plan Priorities for 200I-2003. Canberra Commonwealth Department of Health and Aged Care,; 200I.

19. Commonwealth Department of Health and Aged Care: National Injury Prevention Plan Priorities for 200I-2003. Implementation Plan. Canberra, Commonwealth Department of Health and Aged Care,; 200I.

20. Centre for Accident Research and Road Safety Queensland: Evaluation of the National Injury Prevention Plan: Priorities for 200I-2003 and Evaluation of the National Injury Prevention Plan: Priorities for 200I-2003 Implementation Plan. Canberra , Australian Government Department of Health and Ageing; 2004.

21. National Public Health Partnership: The National Injury Prevention and Safety Promotion Plan: 2004-2014. Canberra National Public Health Partnership; 2004.

22. Colebatch H: Policy. Buckingham, Open University Press; 2002.

23. Considine M: Public policy: a critical approach. Melbourne , Macmillan Education Australia; 1994

24. Finch $C$, Hayen A: Governmental health agencies need to assume leadership in injury prevention. Injury Prevention 2006 , 12:2-3.

25. Accident Compensation Corporation: New Zealand Injury Prevention Strategy. 2005/08 Implementation Plan. Wellington , Accident Compensation Corporation; 2005.

26. Council of Australian Governments: Council of Australian Governments. [http://www.coag.gov.au/].

27. Australian Transport Safety Bureau: Road crash casualties and rates, Australia, 1925 to latest year. [http://www.atsb.gov.au/ publications/2005/pdf//925-present.pdf].

Publish with Bio Med Central and every scientist can read your work free of charge

"BioMed Central will be the most significant development for disseminating the results of biomedical research in our lifetime. "

Sir Paul Nurse, Cancer Research UK

Your research papers will be:

- available free of charge to the entire biomedical community

- peer reviewed and published immediately upon acceptance

- cited in PubMed and archived on PubMed Central

- yours - you keep the copyright 